\title{
Gold nanoparticles induced cloudy swelling to hydropic degeneration, cytoplasmic hyaline vacuolation, polymorphism, binucleation, karyopyknosis, karyolysis, karyorrhexis and necrosis in the liver
}

\author{
Mohamed Anwar K Abdelhalim ${ }^{1^{*}}$ and Bashir M Jarrar²
}

\begin{abstract}
Background: Nanoparticles (NPs) can potentially cause adverse effects on organ, tissue, cellular, subcellular and protein levels due to their unusual physicochemical properties. Advances in nanotechnology have identified promising candidates for many biological and biomedical applications. The aim of the present study was to investigate the particle-size, dose and exposure duration effects of gold nanoparticles (GNPs) on the hepatic tissue in an attempt to cover and understand the toxicity and their potential therapeutic and diagnostic use.

Methods: A total of 70 healthy male Wistar-Kyoto rats were exposed to GNPs received 50 or 100 ul of GNPs infusion of size (10, 20 and $50 \mathrm{~nm}$ for 3 or 7 days) to investigate particle-size, dose and exposure duration effects of GNPs on the hepatic tissue.

Results: In comparison with respective control rats, exposure to GNPs doses has produced alterations in the hepatocytes, portal triads and the sinusoids. The alterations in the hepatocytes were mainly vacuolar to hydropic degeneration, cytopasmic hyaline vacuolation, polymorphism, binucleation, karyopyknosis, karyolysis, karyorrhexis and necrosis.

Conclusions: The hepatocytes swelling might be exhibited as a result of disturbances of membranes function that lead to massive influx of water and $\mathrm{Na}^{+}$due to GNPs effects accompanied by leakage of lysosomal hydrolytic enzymes that lead to cytoplasmic degeneration and macromolecular crowding. Hydropic degeneration is a result of ion and fluid homestasis that lead to an increase of intracellular water. The vacuolated swelling of the cytoplasm of the hepatocytes of the GNPs treated rats might indicate acute and subacute liver injury induced by the GNPs. Binucleation represents a consequence of cell injury and is a sort of chromosomes hyperplasia which is usually seen in regenerating cells. The induced histological alterations might be an indication of injured hepatocytes due to GNPs toxicity that became unable to deal with the accumulated residues resulting from metabolic and structural disturbances caused by these NPs. These alterations were size-dependent with smaller ones induced the most effects and related with time exposure of GNPs. The appearance of hepatocytes cytoplasmic degeneration and nuclear destruction may suggest that GNPs interact with proteins and enzymes of the hepatic tissue interfering with the antioxidant defense mechanism and leading to reactive oxygen species (ROS) generation which in turn may induce stress in the hepatocytes to undergo atrophy and necrosis. More histomorphologcal, histochemical and ultrastrucural investigations are needed in relation of the application of GNPs with their potential role as a therapeutic and diagnostic tool.
\end{abstract}

Keywords: gold nanoparticles, size, hepatic tissue, histology, hydropic degeneration, nanotoxicity, rats

\footnotetext{
* Correspondence: abdelhalimmak@yahoo.com

'Department of Physics and Astronomy, College of Science, King Saud

University, Saudi Arabia

Full list of author information is available at the end of the article
} 


\section{Introduction}

The rats exposed to aerosols of GNPs revealed that the NPs were rapidly taken into the system with the highest accumulation in the lungs, aorta, esophagus and olfactory bulb [1]. Moreover, NPs are believed to be more biologically reactive than their bulk counter parts due to their small size and larger surface area to volume ratio [1,2].

Although some scientists consider NPs as nontoxic, there are other studies reporting the toxic effects of NPs [3-5]. Although some NPs may appear to be nontoxic, other cellular mechanisms such as cell signaling and other normal cellular functions may be disrupted and are currently undergoing further investigation $[6,7]$. The toxicity of NPs is being addressed by number of standardized approaches with in vitro, in vivo as well as detailed genomic or biodistribution studies [7]. It has been shown that NPs may produce in vitro toxicity in some cell-based assays, but not in others. This may be a result of interference with the chemical probes, differences in the innate response of particular cell types, or other factors [8]. In addition, GNPs are used as carriers for the delivery of drugs and genes [9].

Gold in its bulk form has long been considered an inert, noble metal with some therapeutic and even medicinal value hence GNPs are thought also to be relatively noncytotoxic [10]. Yet there are differing reports of the extent of the toxic nature of these particles owing to the different modifications of the GNPs, surface functional attachments and shape and diameter size of the nanospheres $[11,12]$. Moreover, the metallic nature of the metal derived NPs and the presence of transition metals encourages the production of reactive oxygen species (ROS) leading to oxidative stress [13,14].

The histological and the histochemical characterization in the hepatic tissues due to GNPs are not documented and have not yet been identified. In the present study, an attempt has been made to characterize the possible histological alterations in the hepatic tissues following experimental GNPs and, if so, whether are related to the size of these NPs and the time of exposure.

The present study was carried out to investigate the particle-size, dose and exposure duration of GNPs on the hepatic tissue in an attempt to cover and understand the toxicity and their potential therapeutic and diagnostic use in relation with the time of exposure.

\section{Materials and methods}

A total of 70 healthy male Wistar-Kyoto rats obtained from the Laboratory Animal Center (College of Pharmacy, King Saud University, Saudi Arabia). The rats nearly of the same age (12 weeks old) and weighing 220-240 gm of King Saud University colony were used. Animals were randomly divided into groups, 12 GNPs-treated rats groups and one control group (NG). Following a period of stabilization (7 days), 10, 20 and $50 \mathrm{~nm}$ GNPs were administered intraperitonealy at the rate for 3 or 7 days as follows: Group 1: received infusion of $50 \mu \mathrm{l}$ GNPs of size $10 \mathrm{~nm}$ for 3 or 7 days $(\mathrm{n}=10)$; Group 2: received infusion of $50 \mu \mathrm{l}$ GNPs of size $20 \mathrm{~nm}$ for 3 or 7 days $(\mathrm{n}=10)$; Group 3: received infusion of $50 \mu \mathrm{l} \mathrm{GNPs}$ of size $50 \mathrm{~nm}$ for 3 or 7 days $(n=10)$; Group 4: received infusion of $100 \mu \mathrm{l} \mathrm{GNPs}$ of size $10 \mathrm{~nm}$ for 3 or 7 days; $(\mathrm{n}=10)$; Group 5: received infusion of $100 \mu \mathrm{l} \mathrm{GNPs}$ of size $20 \mathrm{~nm}$ for 3 or 7 days $(n=10)$; Group 6: received infusion of $100 \mu \mathrm{l}$ GNPs of size $50 \mathrm{~nm}$ for 3 or 7 days; $(\mathrm{n}=10)$; Control group: received no gold nanoparticles $(\mathrm{n}=10)$.

The rats were maintained on standard laboratory rodent diet pellets and were housed in humidity and temperature-controlled ventilated cages on a $12 \mathrm{~h}$ day/night cycle. Two animals from each group were killed by dislocation of the neck at intervals of 3 and 7 days of treatment with GNPs. All experiments were conducted in accordance with the guidelines approved by King Saud University Local Animal Care and Use Committee.

Fresh portions of the lateral lobes of the liver from each rat were cut rapidly, fixed in neutral buffered formalin $(10 \%)$, then dehydrated, with grades of ethanol $(70,80$, 90, 95 and 100\%). Dehydration was then followed by clearing the samples in 2 changes of xylene. Samples were then impregnated with 2 changes of molten paraffin wax, then embedded and blocked out. Paraffin sections (4-5 um) were stained with hematoxylin and eosin the conventional histological and stain according to Pearse [15]. Stained sections of control and treated rats were examined for alterations in the architecture, portal triads, hepatocytes, sinusoids and for the presence of degeneration, necrosis, fatty change and portal fibrosis.

\section{Results and Discussions}

The 10 and $20 \mathrm{~nm}$ GNPs show spherical shape while the $50 \mathrm{~nm}$ GNPs show hexagonal shape. The mean size for GNPs was calculated from the images taken by the transmission electron microscope (TEM). The $10 \mathrm{~nm}$ GNPs was of mean size $9.45 \pm 1.33 \mathrm{~nm}, 20 \mathrm{~nm}$ GNPs was of mean size $20.18 \pm 1.80$ and the $50 \mathrm{~nm}$ GNPs was of mean size $50.73 \pm 3.58$ [16].

\section{Histological alterations}

GNPs-normal rat demonstrating normal hepatocytes are shown in Figure 1. In comparison with the control group, the following histological alterations were detected in the liver of GNPs treated rats.

\section{Cloudy swelling}

hepatocytes exhibited cloudy swelling with pale cytoplasm and poorly delineated and displaced nuclei in all GNPs treated rats. This ballooning degeneration was more prominent with $100 \mu \mathrm{l}$ dose than $50 \mu \mathrm{l}$ one and with $10 \mathrm{~nm}$ 


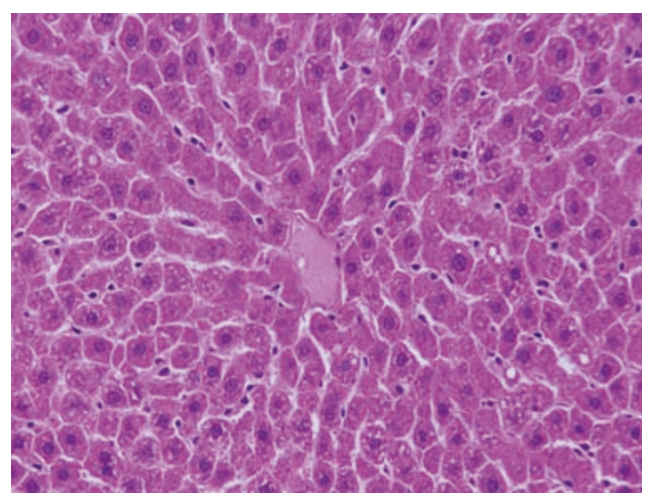

Figure 1 GNPs-normal rat demonstrating normal hepatocytes

size particles than the larger ones (Figure 2a). This swelling might be exhibited as a result of disturbances of membranes function that lead to massive influx of water and $\mathrm{Na}^{+}$due to GNPS effects. Cellular swelling might be accompanied by leakage of lysosomal hydrolytic enzymes that lead to cytoplasmic degeneration and macromolecular crowding [17].

\section{Hydropic degeneration}

vacuolization of the hepatocytes cytoplasm was seen and increased in severity in the liver of rats received $100 \mu \mathrm{l}$ of $10 \mathrm{~nm}$ GNPs with less vacuolar degeneration with larger ones. More vacuolar degeneration was observed in the hepatocytes of rats exposed to 7 days than ones exposed to 3 days (Figure 2b). Hydropic degeneration is a result of ion and fluid homestasis that lead to an increase of intracellular water [18]. The vacuolated swelling of the cytoplasm of the hepatocytes of the GNPs treated rats might indicate acute and subacute liver injury induced by these NPs.

\section{Hyaline inclusions and hayaline vacuolation}

inclusions similar to Mallory hyaline bodies and hayaline vacuolations were detected in the cytoplasm of some hepatocytes of rats received $100 \mu \mathrm{l}$ of $10 \mathrm{~nm}$ GNPs. This alteration was less prominent in rats exposed to larger particles (Figures 2c and 2d).

\section{Nuclear polymorphism}

variable nuclei sizes were observed in some hepatocytes. This change became apparent after 7 days of $50 \mathrm{~nm}$ GNPs administration. Some studies indicate that nuclear polymorphism is seen in hepatic dysplasia and carcinomatous lesion [19].

\section{Karyopyknosis}

pyknotic nuclei were seen in some hepatocytes of GNPs treated rats. Some pyknotic hepatocytes of rats received $100 \mu \mathrm{l}$ of $50 \mathrm{~nm}$ size particles exhibited clumping and

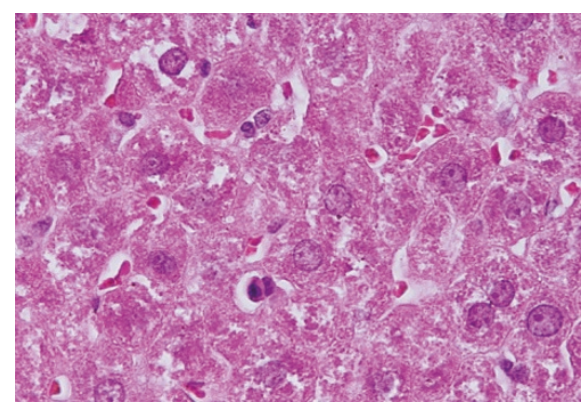

a

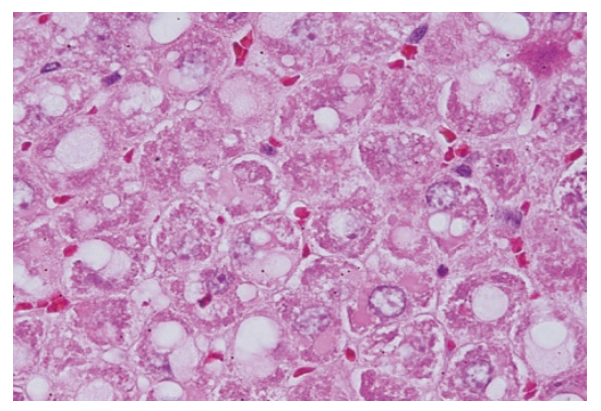

c

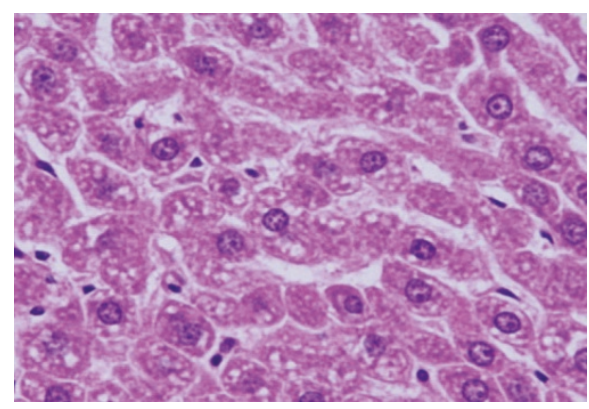

b

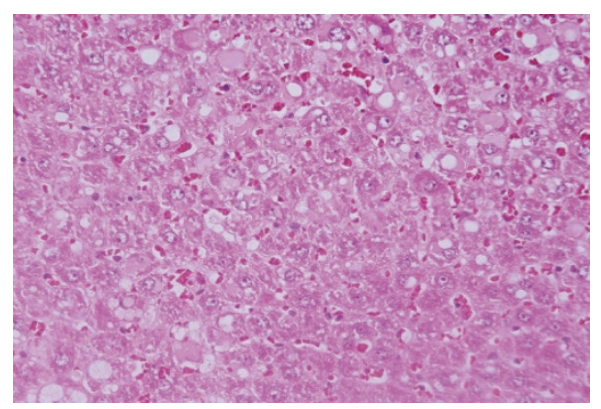

d

Figure 2 GNPs-treated rat. (A) GNPs-treated rat received $50 \mu$ l of 10 nm particles for 3 days demonstrating hepatocytes cloudy swelling. (B) GNPstreated rat received $100 \mu \mathrm{l}$ of $10 \mathrm{~nm}$ particles for 7 days demonstrating hydropic degeneration. (C) GNPs-treated rat received $50 \mu \mathrm{l}$ of $10 \mathrm{~nm}$ particles for 3 days demonstrating hyaline inclusions. (D) GNPs-treated rat received $100 \mu \mathrm{l}$ of $10 \mathrm{~nm}$ particles for 7 days demonstrating hyaline vacuolation. 
condensation of the chromatin materials in the periphery of the nuclei together with irregularity nuclear membranes (Figures 3a and 3b). Karyopyknosis ia an irreversible condensation of chromatin in the nucleus of a cell undergoing necrosis or apoptosis [20].

\section{Karyorrhexis}

some hepatocytes of rats received $50 \mathrm{~nm}$ GNPs showed nucleoli disappearance (Figure 3c). This nuclear damage was more prominent after 7 days of exposure to NPs. Karyorrhexis is a sort of destructive fragmentation of the nucleus proceeded by pyknosis and is followed by karyolysis [21].

\section{Karyolysis}

this alteration appeared mainly in the liver of GNPStreated rats exposed to $100 \mathrm{ul}$ of $50 \mathrm{~nm}$ size particles (Figure 3d). Karyolysis is the complete dissolution of the chromatin matter of a dying cell [22].

\section{Binucleation}

occasional binucleation and to lesser extent polynucleation were observed in GNPs treated rats. This change was more prominent in rats exposed to $100 \mu \mathrm{l}$ of $50 \mathrm{~nm}$ size GNPs (Figures 4a and 4b). Binucleation represents a consequence of cell injury and is a sort of chromosomes hyperplasia which is usually seen in regenerating cells [23].

\section{Necrosis}

sporadic spotty well-defined necrosis was noticed in some hepatocytes of GNPs treated rats (Figure 5a). The insulted cells exhibited highly eosinophilic amorphus cytoplasm with occasional apoptotic characterization (Figure 3l). This alteration was detected in the liver of rats exposed to $10 \mathrm{~nm}$ size particles and to lesser extent with $20 \mathrm{~nm}$ particles but was not seen with those exposed to $50 \mathrm{~nm}$ size particles. Apoptic alteration might be followed organelles swelling specially mitochondria, endoplasmic reticulum and rupture of lysosomes which might lead to amorphous eosinophilic cytoplasm as an initial sign in the sequence of hepatocytes necrosis before shrinking and dissolution of nulei [24]. The seen hepatocytes necrosis due to GNPs exposure might indicate oxidative stress on these cells by glutathione depletion.

\section{Hepatic sinusoids dilatation}

hepatic sinusoids were more dilated in rats received $50 \mu \mathrm{l}$ of $10 \mathrm{~nm}$ GNPs than those exposed to larger particles (Figure 5b). This alteration was almost the same among rat exposed to GNPs for 3 or 7 days. This vascular

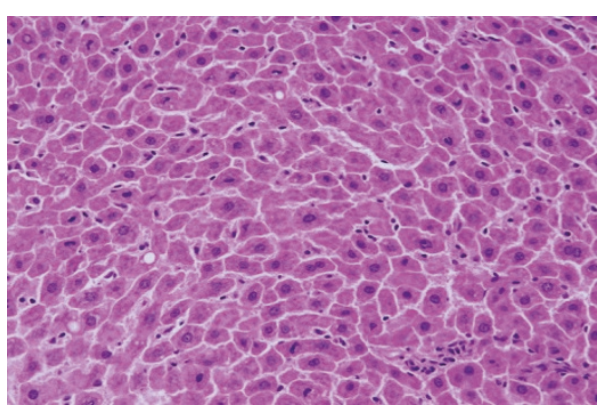

a

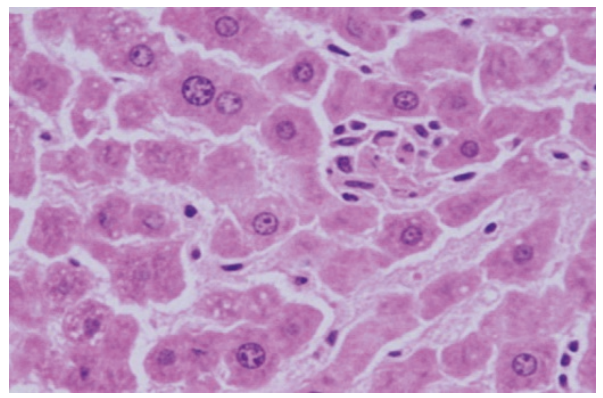

c

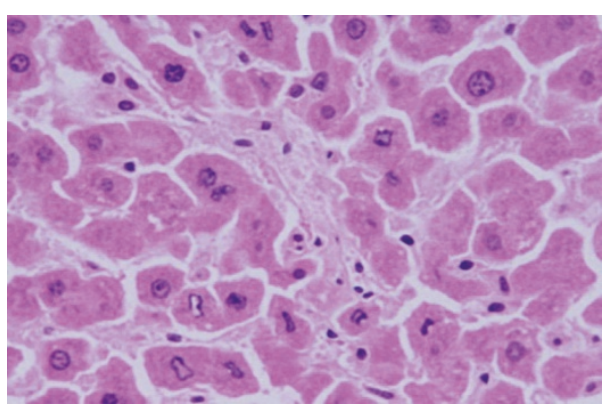

b

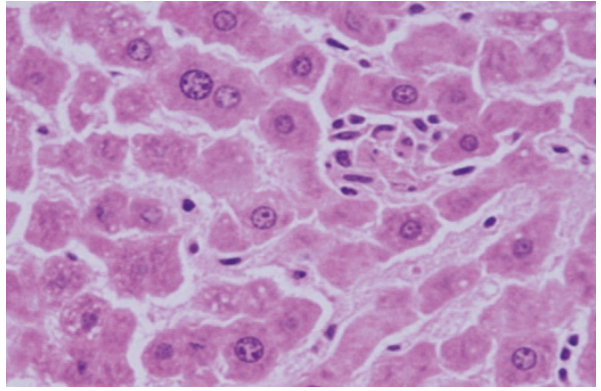

d

Figure 3 GNPs-treated rat. (A) GNPs-treated rat received $100 \mu \mathrm{l}$ of $50 \mathrm{~nm}$ particles for 3 days demonstrating pyknotic hepatocytes. (B) GNPstreated rat received $100 \mu \mathrm{l}$ of $50 \mathrm{~nm}$ particles for 3 days demonstrating clumping and condensation of the chromatin materials in the periphery of the nuclei together with irregularity nuclear membranes. (C) GNPs-treated rat received $50 \mu \mathrm{l} \mathrm{of} 50 \mathrm{~nm}$ particles for 7 days demonstrating karyorrhexis. (D) GNPs-treated rat received $100 \mu \mathrm{l}$ of $50 \mathrm{~nm}$ particles for 7 days demonstrating karyolysis. 


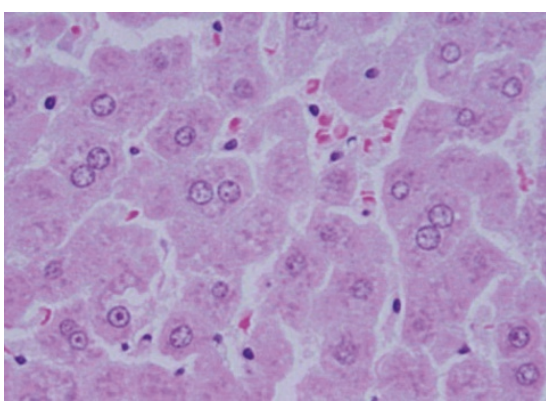

a

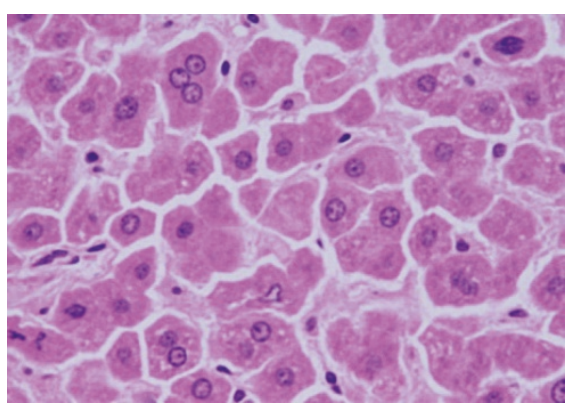

b

Figure 4 GNPs-treated rat. (A) GNPs-treated rat received $100 \mu$ l $50 \mathrm{~nm}$ particles for 3 days demonstrating binucleation. (B) GNPs-treated rat received $100 \mu \mathrm{l}$ of $20 \mathrm{~nm}$ particles for 7 days demonstrating binucleation.

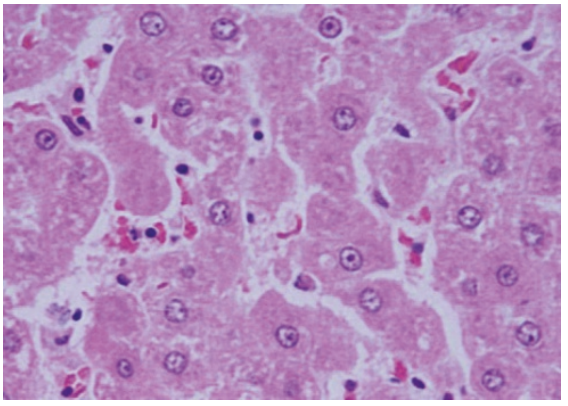

a

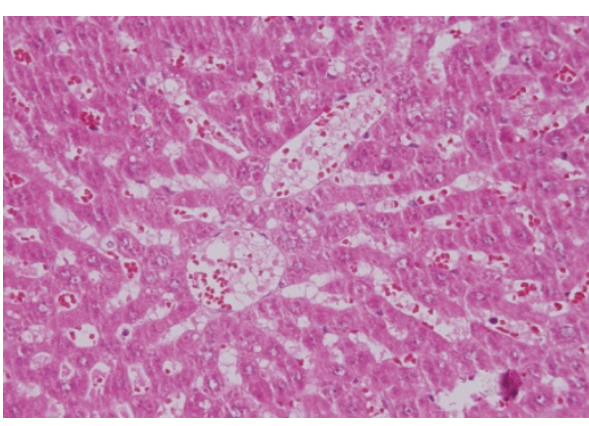

b

Figure 5 GNPs-treated rat. (A) GNPs-treated rat received $50 \mu \mathrm{l}$ of $10 \mathrm{~nm}$ particles for 3 days demonstrating necrotic hepatocytes. (B) GNPstreated rat received $50 \mu \mathrm{l}$ of $10 \mathrm{~nm}$ particles for 3 days demonstrating hepatic sinusoidal dilatation.

alteration is characterized by focal dilatation of sinusoidal spaces associated hepatocytes atrophy and necrosis [25].

Abdelhalim and Bashir, 2011 have reported that GNPstreated rat received $100 \mu \mathrm{l}$ of $10 \mathrm{~nm}$ particles for 7 days demonstrating apoptotic characterization, GNPs-treated rat received $100 \mu \mathrm{l}$ of $10 \mathrm{~nm}$ particles for 3 days demonstrating inflammatory cell infiltration, GNPs-treated rat received $50 \mu \mathrm{l}$ of $10 \mathrm{~nm}$ particles for 7 days demonstrating Kupffer cells hyperplasia, GNPs-treated rat received $100 \mu \mathrm{l}$ of $10 \mathrm{~nm}$ particles for 7 days demonstrating hepatic fatty degeneration and GNPs-treated rat received $50 \mu \mathrm{l}$ of $20 \mathrm{~nm}$ particles for 7 days demonstrating hepatic central vein intima disruption [16].

None of the above alterations were observed in the liver of any member of the control group (Figure 1).

\section{Conclusions}

Histological alterations by GNPs exposure as shown in the results of the present work could be an indication of injured hepatocytes due to GNPs toxicity that become unable to deal with the accumulated residues resulting from metabolic and structural disturbances caused by these particles. One might conclude that these alterations are size-dependent with smaller ones induced more damage with relation with the time exposure of GNPs.

The appearance of hepatocytes cytoplasmic degeneration and nuclear destruction may suggest that GNPs interact with proteins and enzymes of the hepatic tissue interfering with the antioxidant defense mechanism and leading to reactive oxygen species (ROS) generation which in turn may induce stress in the hepatocytes to undergo atrophy and necrosis.

More histomorphological, histochemical and ultrastructural investigations are needed to correlate the biomedical application of GNPs with the potential threat of their therapeutic and diagnostic use.

\section{Acknowledgements}

The authors are very grateful to National Plan of Science and Technology (NPST). This research was financially supported by the National Science and Technology Innovation Plan (NSTIP), Research No. 08-ADV206-02 and Research No. 09-NAN670-02, College of Science, King Saud University, Saudi Arabia.

\section{Author details}

'Department of Physics and Astronomy, College of Science, King Saud University, Saudi Arabia. ${ }^{2}$ College of Applied Medical Sciences, Al-Jouf University, P.O. Box 2014, Skaka - Al-Jouf, Saudi Arabia. 


\section{Authors' contributions}

MAKA and BMJ have analyzed data, interpreted and written the final draft of this manuscript. The animal model used in this study was obtained from the Laboratory Animal Center (College of Pharmacy, King Saud University, Saudi Arabia). MAKA has conceived the study and its design and obtained research grants for this study. Moreover, both authors have read and approved the final manuscript.

\section{Competing interests}

The authors declare that they have no competing interests.

Received: 7 August 2011 Accepted: 22 September 2011 Published: 22 September 2011

\section{References}

1. Lanone S, Boczkowski J: Biomedical applications and potential health risks of nanomaterials: molecular mechanisms. Curr Mol Med 2006 6:651-63.

2. Yu LE, Yung L-YL, Balasubramaniam KS, Hartono D, et al: Translocation and effects of gold nanoparticles after inhalation exposure in rats. Nanotoxicology 2007, 1(3):235-42.

3. Chithrani BD, Chan WC: Elucidating the mechanism of cellular uptake and removal of protein-coated gold nanoparticles of different sizes and shapes. Nano Lett 2007, 7:1542-1550.

4. Pan Y, Neuss S, Leifert A, Fischler M, Wen F, Simon U, Schmid G, Brandau W, Jahnen-Dechent W: Size-dependent cytotoxicity of gold nanoparticles. Smal 2007, 3:1941-1949.

5. BarathManiKanth S, Kalishwaralal K, Sriram M, Pandian SRK, Youn H, Eom S, Gurunathan S: Anti-oxidant effect of gold nanoparticles restrains hyperglycemic conditions in diabetic mice. Journal of Nanobiotechnology 2010, 8:16

6. Hussain $S M$, Hess KL, Gearhart JM, Geiss KT, Schlager JJ: In vitro toxicity of nanoparticles in BRL- 3A rat liver cells. Toxicol in Vitro 2005, 19:975-983.

7. Schrand AM, Bradich-Stolle LK, Schlager JJ, Dai L, Hussain SM: Can silver nanoparticles be useful as potential biological labels? Nanotechnology 2008, 9:1-13.

8. Shaw SY, Westly EC, Pittet MJ, Subramanian A, Schreiber SL, Weissleder R. Perturbational profiling of nanomaterial biologic activity. Proc Natl Acad Sci USA 2008, 105:7387-7392.

9. Gibson JD, Khanal BP, Zubarev ER: Paclitaxel-functionalized gold nanoparticles. J Am Chem Soc 2007, 129:11653-11661.

10. Connor EE, Mwamuka J, Gole A, Murphy CJ, Wyatt MD: Gold nanoparticles are taken up by human cells but do not cause acute cytotoxicity. Small 2005, 1(3):325-327.

11. Takahashi H, Niidome Y, Niidome T, Kaneko K, Kawasaki H, Yamada S: Modification of gold nanorods using phosphatidylcholineto reduce cytotoxicity. Langmuir 2006, 22(1):2-5.

12. Neuss S, Leifert A, Fischler M, Wen F, Simon U, et al: Size-dependent cytotoxicity of gold nanoparticles. Small 2007, 3(11):1941-1949.

13. MacNee W, Donaldson K: Mechanism of lung injury caused by PM10 and ultrafine particles with special reference to COPD. Eur Respir J 2003, 21(40):47S-51S.

14. Jia HY, Liu Y, Zhang XJ, Han L, Du LB, Tian Q, et al: Potential oxidative stress of gold Nanoparticles by induced-NO releasing in serum. J am Chem Soc 2009, 131(1):40-1.

15. Pearse AE: Histochemistry. Theoritical and applied. In Analytical technology. Volume 2.. 4 edition. Churchill-Livingstone, Edinburgh; 1985.

16. Abdelhalim MAK, Jarrar BM: Gold nanoparticles administration induced prominent inflammatory, central vein intima disruption, fatty change and Kupffer cells hyperplasia. Lipids in Health and Disease 2011, 10:133.

17. Del Monte U: Swelling of hepatocytes injured by oxidative stress suggests pathological changes related to macromolecular crowding. Medical Hypotheses 2005, 64(4):818-825.

18. Schrand AM, Rahman MF, Hussain SM, Schlager JJ, David A, Smith DA, Syed: Metal-based nanoparticles and their toxicity assessment. Nanomed Nanobiotechnol 2010, 2:544-568.

19. Zusman I, Kozlenko M, Zimber A: Nuclear polymorphism and nuclear size in precarcinomatous and carcinomatous lesions in rat colon and liver. Cytometry 1991, 12(4):302-7.

20. Kumar V, Abbas A, Nelson F, Mitchell R: Robbins Basic Pathology. Robbins Basic Pathology 2007, 6:9-10.
21. Zamzami N, Kroemer G: Apoptosis: Condensed matter in cell death". Nature 1999, 401(127):127-8.

22. Cotran, Kumar, Collins : Robbins Pathologic Basis of Disease. Philadelphia: W.B Saunders Company; 1998.

23. Gerlyng1 P, Åbyholm1 A, Grotmol T, Erikstein B, Huitfeldt HS, Stokke T, Seglen1 PO: Binucleation and polyploidization patterns in developmental and regenerative rat liver growth. Cell Proliferation 2008, 26(6):557-565.

24. Pandey G, Srivastava DN, Madhuri S: A standard hepatotoxic model produced by paracetamol in rat. Toxicology International 2008, 15(1):69-70.

25. Johar D, Roth JC, Bay GH, Walker JN, Kroczak TJ, Los M: Inflammatory response, reactive oxygen species, programmed (necrotic-like and apoptotic) cell death and cancer. Rocz Akad Med Bialymst 2004, 49:31-9.

doi:10.1186/1476-511X-10-166

Cite this article as: Abdelhalim and Jarrar: Gold nanoparticles induced cloudy swelling to hydropic degeneration, cytoplasmic hyaline vacuolation, polymorphism, binucleation, karyopyknosis, karyolysis, karyorrhexis and necrosis in the liver. Lipids in Health and Disease 2011 10:166

\section{Submit your next manuscript to BioMed Central and take full advantage of:}

- Convenient online submission

- Thorough peer review

- No space constraints or color figure charges

- Immediate publication on acceptance

- Inclusion in PubMed, CAS, Scopus and Google Scholar

- Research which is freely available for redistribution 